\title{
Coordinating Biomass Supply Chains for Remote Communities: A Comparative Analysis of Non-cooperative and Cooperative Scenarios
}

Fereshteh Mafakheri*, Concordia Institute for Information Systems Engineering (CIISE), Concordia University, Montreal, QC, H3G 1M8, Canada

Dotun Adebanjo, Business School, University of Greenwich, Greenwich, London SE10 9LS, UK

Audley Genus, Kingston Business School, Kingston University, Kingston upon Thames KT2 7LB

\begin{abstract}
The absence of economies of scale is a major barrier in use of renewable energy sources in small and dispersed off-grid remote communities. For example, in northern Canada, diesel is currently the main source of electricity and heat generation. Coordination of biomass supply chains could play a key role in improving the cost efficiency and reliability of bioenergy generation through bundled ordering and creation of storage hubs. In this study, a supply chain management model with multiple suppliers and multiple end-user communities is formulated. The proposed model enables us to analyse and compare the outcomes of adopting a cooperative coordination strategy (with a joint pay-off for communities) versus a non-cooperative coordination strategy (with individual payoffs for communities). Other peculiar attributes of the proposed model rest in the addressing of restricted ordering schedules and quantities (due to unavailability of pathways) by advocating nonlinear ordering and distribution costs (to incorporate quantity discounts) achieved through coordinated and/or collective inventories. A real biomass supply chain case study of three northernmost Nunavik communities in Quebec is considered to show the applicability of the model and provide insights for uptake of bioenergy sources in remote off-grid communities.
\end{abstract}

Keywords: Bioenergy; supply chain coordination; optimization; scheduling; logistics; remote communities

\footnotetext{
*Corresponding author, Email: f.mafakheri@ concordia.ca
} 


\section{Introduction}

Energy supply is a key factor for survival of the communities in northern Canada and in maintaining and enhancing the quality of life for citizens of this region, given the extreme weather conditions experienced in this part of Canada. Lack of connectivity to the main grid and other permanent carriers of energy sources (such as pipelines) have forced these communities to rely on stand-alone off-grid energy generation facilities (Natural Resources Canada (NRCan) 2011). The vast majority of these remote communities rely on fossil fuels, and in particular diesel, as the main source of energy (National Energy Board (NEB) 2016). Diesel is mostly shipped from the major cities (in the south) in spring and summer via the waterways or roads depending on their availability (e.g. mainly covered by ice in the winter). The reliance on one type of fuel and its supply chain has made these communities even more vulnerable.

A transition to renewable sources of energy in northern Canada could not only diversify the supply mix, enhancing the resilience of the communities, but also would be a step towards reducing the generation of greenhouse gas emissions in Canada. However, the remoteness and dispersion of these small northern communities diminishes the economies of scale. In that sense, the fixed (and mostly capital) costs associated with energy production facilities will be spread across smaller quantities of energy increasing the unit cost of energy production (per Kwh). This has been a discouragement for investment in building and maintaining renewable energy facilities in the region. In addition, the generated energy from renewable sources could be less affordable for the residents compared to the diesel option (NEB 2016).

In comparison with diesel, biomass is well positioned to be used as a replacement or back-up fuel in northern communities due to its carbon abatement potentials. As a fuel-based option, it could be transported to the region through similar logistics arrangements that exist for diesel with a number of shipment companies (Rahman 2014). It is worth mentioning that the biomass from agricultural and forestry residues is abundant across Canada (Paré et al. 2011), from diverse/varied materials, locations and suppliers.

In comparison with other renewable energy sources, biomass facilities are typically associated with a lower levelized capital and operational cost (excluding hydro) (Ellabban et al. 2014, IRENA 2018). The levelized cost of electricity (LCOE) is established by calculating the total cost of 
electricity generation (capital and operation \& maintenance) over the service life of facilities and distributing it per unit of electricity generated (International Renewable Energy Association (IRENA) 2018). LCOE could be calculated with inclusion or exclusion of fuel costs. In Canada, the levelized costs of electricity generation from wind, solar, and biomass are reported in ranges of $[0.07,0.31]$, [0.11,0.35], and [0.06,0.26] in $\$ / \mathrm{KWh}$, respectively (NEB 2017). The energy conversion and loading factors of biomass energy facilities are also higher than that of wind and solar energy technologies (Ellabban et al. 2014; Sun et al. 2018). The loading factor is a measure corresponding to the efficiency of energy production calculated as the ratio of average (generated) energy to the demand (at peak) (IRENA 2018). From a technological perspective, it could represent the percentage of facility uptime with electricity output. Moreover, small scale bioenergy technologies are manufactured with high levels of standardization, while the solar and wind technologies are mostly project-based and their performance highly depends on the characteristics of each specific site. In addition, the focus on solid biomass stems from the fact that liquid (woodbased) biodiesel is much more costly (Sarkar et al., 2011) and has poorer environmental performance due to the large consumption of non-renewable resources as well as carbon emissions during the ethanol production process (Neupane, et al., 2013). Therefore, biomass is an available and potentially efficient energy source for stakeholders wishing to seek alternatives to legacy energy sources such as diesel. As such, the use of biomass as a source for energy generation has increased by 35\% in terms of installed capacities in northern Canada since year 2006 (NEB 2016).

In general, bioenergy supply chain management has several peculiar attributes (Rentizelas et al. 2009; Grant and Clarke 2010; Mafakheri and Nasiri 2014; Nasiri et al. 2016; Sun et al. 2018; Zandi Atashbar et al. 2018). Variation in type and quality of biomass materials imposes varied transportation and storage requirements in order to minimize moisture accumulation or spoilage. In addition, some sources of biomass materials (such as agricultural residues) are not available throughout the year or their supply fluctuates considerably over time (Yazan et al. 2011).

There are several specific challenges with respect to the supply of biomass to northern communities. First, biomass materials are diverse and their suppliers are spatially dispersed in Canada, with varied supply capacities and variability, making it challenging to recognize a specific biomass supply pathway for remote communities in northern Canada (Canadian Bioenergy Association (CanBio) 2014). The communities, on the other hand, are also spatially dispersed. Such 
attributes elevate the risk of biomass supply discontinuity and shortage against the backdrop of extreme weather conditions in the north (and the greater need for continuous supply of energy). Consequently, aggregated biomass inventories and supply chain coordination are part of the solutions to improve the economies of scale and reduce the associated risks for adoption of biomass energy in northern communities in Canada.

In the sense of the above facts, this study proposes a bioenergy supply chain coordination model incorporating biomass hubs to address the efficiency and logistics challenges. The model incorporates the peculiar attributes of the remote communities including geographical dispersion, absence of economies of scale, and accessibility perspectives. There could be two pathways for coordination. A non-cooperative scenario in which the supply of biomass is coordinated (i.e. coordination of suppliers), and a cooperative scenario in which both supply and ordering (demand) of biomass are coordinated (i.e. coordination of suppliers and demand from the communities). In the non-cooperative coordination scenario, each community optimizes its own payoff with access to aggregated inventories at hubs. In the cooperative coordination scenario, a collective pay-off is optimized with access to collective inventories as well as orders through hubs. In doing so, the model enables us to get insights into the impact of ordering restrictions (on order quantities and timings), purchase and distribution quantity discounts, as well as collective inventories in enhancing the share of biomass under each coordination scenario.

In the following sections, first, a literature review is presented on supply chain coordination. A description of the proposed model is then provided along with the details of the governing constraints and requirements in both coordination cases. A case study of select communities in northern Quebec will be investigated followed by an analysis of the results and discussions. Finally, the paper concludes by summarizing the key elements of the proposed model, the case study, assumptions and limitations, as well as avenues for future research.

\section{Literature Review}

This section examines the literature that underpins this research and focuses primarily on the nature and benefits that previous research has attributed to supply chain coordination. A particular attention is given to highlight the literature about supply chain coordination when the ordering and 
supply quantities are small and there is restriction on delivery schedules while the demand is steady. These characteristics resemble the case of biomass supply to remote communities. As such, the potential import for a biomass supply chain coordination approach and model for northern remote communities in Canada is then discussed by integrating three mainstream supply chain coordination mechanisms identified in the literature paving the path for the propositions that follow in the methodology section.

Supply chain coordination accounts for vertical arrangements (in form of partnership contracts) among various layers of supply chains (supplier, retailer, and end-user of products) or horizontal alignments (in form of cooperation and collective decision making) among competitors (excluding suppliers) (Chan 2019). The main target of a coordination scheme is to either increase the profitability of involved parties (Chaharsooghi and Heydari 2010) or reduce the risk of back orders (Mena et al. 2013; Giri and Bardhan 2015; Cai et al. 2019). There are various mechanisms suggested in the literature to establish supply chain coordination.

Quantity discounts have been considered as a means of coordination to encourage retailers to establish higher inventories, thereby minimizing backorders (Heydari 2014; Huang et al. 2015; Sarkar 2016). A quantity discount as a sole coordination mechanism could motivate retailers to extend their ordering times in order to increase the quantity of each order (less frequent orders in bigger batches), increasing the risk of back orders (Zhang et al. 2014). To address this issue, advance order payments, in combination with quantity discounts, have been proposed as a way of ensuring on-time orders from retailers (Zhang et al. 2014; Tong et al. 2019). Temporary and timebased quantity discounts are also suggested to serve as incentives not only for the quantity of orders, but also for the timing of deliveries (Alaei and Setak 2015). Consequently, an optimal schedule for the discounts (as a function of quantity and time) was proposed, which allocates the incentives on a temporary basis such that to encourage suppliers' commitment to on-time deliveries.

Revenue/cost sharing is also considered as an alternative mechanism to encourage alignment of involved parties in a partnership model (Hou et al. 2017). Mafakheri and Nasiri (2013) proposed a leader-follower revenue-sharing game in a two-echelon supply chain of supplier-retailer. They explored the assignment of a leadership position (the party that offers shared revenues) to supplier and retailer, and compared the performance of each setting from cost and environmental 
perspectives. Oliviera et al. (2013) have analysed the impact of bilateral (revenue or cost sharing) contracts, as a means of supply chain coordination, in the electricity industry, using a game theoretic model. They have suggested a two-part tariff as the best bilateral contract option in improving the efficiency and profitability of the suppliers.

Finally, multi-level inventory planning has also been investigated as a means of promoting coordination in supply chains. This network scale approach is particularly well-suited to fostering coordination among demand points with small order quantities (such as communities of the northern Quebec). This approach could improve the economies of scale in the long-term (through establishing aggregated distribution inventories) and minimizing the risk of shortage in short-term (through maintaining local retailer/end user inventories). There are several examples of supply chain models with multi-level inventories in the literature. Ganeshan (1999) proposed a single objective cost minimization model for a supply chain network consisting of multiple suppliers and retailers as well as a single warehouse as the distribution and coordination point. The holding, ordering, and transport costs for maintaining inventories at the retailers and warehouse were incorporated into the above mentioned objective function to direct a coordinated inventory plan consisting of optimal order quantities and their schedule. Minner (2003) presented a survey of supply chain network models with multi-level inventories at the supplier, distribution, and retailer points. They concluded that the incorporation of suppliers' competition, through offering preferential pricing and quantity discounts, has not been explored in the literature. Shahabi et al. (2013) presented an integrated supply chain coordination model with addition of hubs into the supply chain network. The hubs serve as a consolidating point for the retailers with proximate locations, thus improving the economies of scale by reducing the unit transport and holding costs. Their proposed model, however, did not consider a capacity for the hubs and the suppliers' prices did not involve a quantity discount.

Considering the earlier mentioned challenges in biomass supply chains, in particular as relates to remote communities, this paper proposes integration of the mainstream supply chain coordination mechanisms of quantity discounts, cost sharing, and multi-level inventories with incorporation of biomass storage hubs. The hubs will serve as the main driver to coordinate ordering and/or storage activities for targeted communities and to enhance the economies of scale for a biomass supply chain network of spatially dispersed suppliers and communities. In particular, 
the hubs could trigger higher quantity discounts in biomass purchasing and transport. This bi-level inventory planning approach (with storage capacities at hubs and communities) will reduce the risk of biomass shortage, as the local storage capacities in communities will be arranged to meet the short-term needs of the communities while the hubs could secure a steady supply of biomass throughout the year. In addition, the proposed model could consider the possibility of switching to an alternative fuel (i.e. diesel) in case of biomass shortage or if/when the marginal cost of energy production from biomass surpasses that of the alternative fuel (Nasiri et al 2016). We will consider alternative biomass supply chain coordination scenarios with cost sharing among communities (cooperative scenario) and without cost sharing among them (non-cooperative). Considering these coordination arrangements, in the following section, a bi-level and bi-fuel energy supply chain optimization model will be formulated to identify the optimal schedule for production of energy from biomass and diesel, the optimal order quantities and schedule from suppliers and hubs, and the subsequent inventory requirements at the community and hub levels.

\section{Methodology}

Reflecting on the case of biomass supply chains for northern Canada, a network comprising of enduser communities and biomass suppliers is considered. As these communities are relatively small, a collective (bundled) delivery of biomass from suppliers to these communities could improve the economies of scale by reducing the unit costs resulting from transport. The bundling of deliveries could also attract pricing discounts from biomass suppliers. This bundling (coordination) of biomass deliveries could be in place through a shared biomass purchase-distribution channel (hubs) with or without a joint cost sharing agreement (cooperation) of the receiving communities. The former situation would be a cooperative coordination, whereas the latter points to a non-cooperative coordination. As such, the multiplicity of these communities justifies the incorporation of biomass storage hubs as not only a place to establish aggregated (coordinated) inventories, but also a mechanism to cluster the communities from a biomass distribution perspective. These communities could be involved in such an arrangement independently (non-cooperatively) or through a joint cost sharing agreement (cooperatively).Figure 1 presents a generic representation of a supply chain network with suppliers, hubs and local inventories (i.e. the end user communities). 
Each hub is expected to be served by a subset of the participating suppliers based on their price, distance and transport cost. A hub is also expected to serve as a representative point for participating communities given their distance and geographical dispersion. Therefore, an optimization model representing such a network for biomass supply to northern communities shall consider the possible pathways between suppliers and hubs as well as the clustered communities served by each hub. In addition, to enhance the economies of scale, optimal coordinated inventory plans and ordering (delivery) quantities and schedules at the hub and local storage shall be identified during the planning horizon. On that basis, the switching (substitution) schedule between alternative fuels (biomass and diesel) will also be directed.

In the sequel, a supply chain network optimization model is proposed. This model could be formulated under a non-cooperative coordination scenario with individual communities minimizing their individual costs or a cooperative coordination scenario minimizing a total collective cost of biomass supply chain network with a substitute fuel (diesel) as back-up. Collective quantity discounts as well as aggregation of inventories in hubs are considered as the means of fostering the coordination of biomass orders and deliveries. In addition, higher end-user energy prices (several times more than southern cities) could act as an incentive for diversification of fuel sources. Due to these discounts/incentives, prices and costs will be influenced by quantities leading to a nonlinear (quadratic) biomass supply chain network optimization problem.

Over a planning horizon of $T$ (i.e. $t=1,2, \ldots T$ ), the costs are comprised of purchasing/delivery costs from the point of supply, holding cost at the hubs, delivery costs from hubs to local inventories, holding cost at local inventories, and energy conversion costs from biomass and the alternative fuel.

In a non-cooperative coordination scenario, each community optimizes its own payoff represented by Eq. 1.1 (that includes cost of biomass ordering from hubs, local storage costs, and energy generation cost). The hub will also act as an individual player maximizing its payoff represented by Eq. 1.2 (that includes revenue from selling biomass to communities as well as sourcing and hub storage costs). This will pose a multi-objective optimization problem as follows:

Minimize $\quad C_{j}{ }^{(T)}=\sum_{t=0}^{T}\left[\alpha_{j} \cdot I_{j}{ }^{(t)}+\gamma_{j} \cdot z_{j}{ }^{(t)}+\delta_{j} \cdot\left[D_{j}{ }^{(t)}-z_{j}{ }^{(t)}\right]+\sum_{k=1}^{K} \beta_{k j}{ }^{(t)} \cdot y_{k j}{ }^{(t)}\right]$ 
Maximize $\quad H^{(T)}=\sum_{t=0}^{T}\left[\sum_{j=1}^{N} \sum_{k=1}^{K} \beta_{k j}{ }^{(t)} \cdot y_{k j}{ }^{(t)}-\sum_{i=1}^{M} \sum_{k=1}^{K} p_{i k}{ }^{(t)} \cdot x_{i k}{ }^{(t)}-\sum_{k=1}^{K} H_{k} \cdot h_{k}{ }^{(t)}\right]$

$$
\{i=1,2, \ldots M \text { (supliers); } j=1,2, \ldots N \text { (communities); } k=1,2, \ldots K \text { (hubs) }\}
$$

In a cooperative coordination scenario, a collective payoff (including the costs associated with biomass sourcing (purchasing and transport from suppliers), hub storage, delivery to communities, storage at communities, and energy generation) optimized as presented in Eq. 1.3:

$$
\begin{aligned}
& \text { Minimize } \quad C^{(T)}=\sum_{t=0}^{T} \sum_{i=1}^{M} \sum_{k=1}^{K} p_{i k}{ }^{(t)} \cdot x_{i k}{ }^{(t)}+\sum_{t=0}^{T} \sum_{k=1}^{K} H_{k} \cdot h_{k}{ }^{(t)} \\
& +\sum_{t=0}^{T} \sum_{k=1}^{K} \sum_{j=1}^{N} \beta_{k j}{ }^{(t)} \cdot y_{k j}{ }^{(t)}+\sum_{t=0}^{T} \sum_{j=1}^{N} \alpha_{j} \cdot I_{j}{ }^{(t)} \\
& \quad+\sum_{t=0}^{T} \sum_{j=1}^{N} \gamma_{j} \cdot z_{j}{ }^{(t)}+\sum_{t=0}^{T} \sum_{j=1}^{N} \delta_{j} \cdot\left[D_{j}{ }^{(t)}-z_{j}{ }^{(t)}\right]
\end{aligned}
$$

The decision variables are as follows:

$x_{i k}{ }^{(t)}$ : Biomass delivery from supplier ' $i$ ' to hub centre ' $k$ ' at time ' $t$ ' $(\mathrm{Kg})$

$y_{k j}{ }^{(t)}$ : Biomass delivery from hub ' $k$ ' to community ' $j$ ' at time ' $t$ ' (eKg)

$z_{j}{ }^{(t)}$ : Electricity generation from biomass in community ' $j$ ' at time ' $t$ ' (KWh)

And parameters of the model are listed as follows:

$p_{i k}{ }^{(t)}$ : Biomass price (including transportation) offered by supplier ' $i$ ' for delivery to hub centre ' $k$ ' at time ' $t$ ' $(\$ / \mathrm{Kg})$

$H_{k}$ : Holding cost at hub ' $k$ ' per unit of time $(\$ / \mathrm{Kg})$

$h_{k}{ }^{(t)}$ : Biomass inventory level at hub ' $k$ ' at time ' $t$ ' $(\mathrm{Kg})$ 
$\beta_{k j}{ }^{(t)}$ : Biomass ordering/delivery cost from hub ' $k$ ' to community ' $j$ ' at time ' $t$ ' $(\$ / \mathrm{Kg})$

$\alpha_{j}$ : Holding cost at local biomass inventory of community ' $j$ ’ per unit of time $(\$ / \mathrm{Kg})$

$I_{j}^{(t)}$ : Local biomass inventory level at community ' $j$ ' at time ' $t$ ' $(\mathrm{Kg})$

$r_{k j}$ : Delivery time between hub ' $k$ ' and community ' $j$ ' (Month)

$\gamma_{j}$ : Levelized biomass-to-electricity conversion cost in community ' $j$ ' including capital and operational costs $(\$ / \mathrm{KWh})$

$\delta_{j}$ : Levelized electricity generation cost from alternative (diesel) fuel in facility of community ' $j$ ' at time ' $t$ ' including capital, operational and fuel costs $(\$ / K W h)$

$D_{j}^{(t)}$ : Electricity demand of community ' $j$ ' at time ' $t$ ' $(\mathrm{KWh})$

$t_{i k}$ : Delivery time between supplier ' $i$ ' and hub ' $k$ ' (Month)

$f_{j}$ : Biomass conversion rate in biomass-to-electricity conversion facility of community ' $j$ ' $(\mathrm{KWh} / \mathrm{Kg})$

$Z_{j}$ : Capacity of biomass electricity generation facility in community ' $j$ ' (KW)

$\theta_{j}$ : Loading factor of biomass electricity generation facility in community ' $j$ '

$I_{j}$ : Capacity of local biomass inventory at community ' $j$ ' $(\mathrm{Kg})$

$h_{k}$ : Capacity of hub ' $k$ ' (Kg)

$S_{i}$ : Biomass supply capacity of supplier ' $i$ ' $(\mathrm{Kg})$

$p_{i}^{U}$ : Biomass price of supplier ' $i$ ' with no discount $(\$ / \mathrm{Kg})$

$p_{i}^{L}$ : Biomass price of supplier ' $i$ ' with full discount $(\$ / \mathrm{Kg})$

$\beta_{k j}^{U}$ : Biomass order/delivery cost from hub ' $k$ ' to community ' $j$ ’ with no discount $(\$ / \mathrm{Kg})$

$\beta_{k j}^{L}$ : Biomass order/delivery cost from hub ' $k$ ' to community ' $j$ ' with full discount $(\$ / \mathrm{Kg})$ 
Subject to the following constraints:

- Inventory levels at the local storage points:

$$
I_{j}^{(t)}=I_{j}^{(t-1)}+\sum_{k=1}^{K} y_{k j}^{\left(t-r_{k j}\right)}-z_{j}^{(t)} / f_{j} ; I_{j}^{(0)}=0
$$

- Inventory levels at the hubs (with arrivals from clustered sources and departures to targeted communities):

$$
h_{k}{ }^{(t)}=h_{k}{ }^{(t-1)}+\sum_{i=1}^{M} x_{i k}{ }^{\left(t-t_{i k}\right)}-\sum_{j=1}^{N} y_{k j}{ }^{(t)} ; h_{k}{ }^{(0)}=0
$$

- Biomass energy production levels (subject to demand profile of the communities):

$$
z_{j}^{(t)} \leq \operatorname{Min}\left(720 * \theta_{j} * Z_{j}, D_{j}^{(t)}\right)
$$

- Local storage capacities:

$$
0 \leq I_{j}^{(t)} \leq I_{j}
$$

- Storage capacities at the hubs:

$$
0 \leq h_{k}^{(t)} \leq h_{k}
$$

- Suppliers' capacities (for biomass purchase):

$$
\sum_{k=1}^{K} x_{i k}^{(t)} \leq S_{i}
$$

- Biomass pricing with quantity discounts from the suppliers (as a function of purchase and capacities):

$$
p_{i k}^{(t)}=p_{i}^{U}-\left(p_{i}^{U}-p_{i}^{L}\right) \frac{x_{i k}^{(t)}}{s_{i}}
$$

- Distribution costs with quantity discounts for biomass deliveries from hubs:

As a function of individual orders and hub capacities (in non-cooperative scenario): 


$$
\beta_{k j}{ }^{(t)}=\beta_{k j}^{U}-\left(\beta_{k j}^{U}-\beta_{k j}^{L}\right) \frac{y_{k j}\left(t-r_{k j}\right)}{h_{k}}
$$

As a function of collective orders and hub capacities (in cooperative scenario):

$$
\beta_{k j}{ }^{(t)}=\beta_{k j}^{U}-\left(\beta_{k j}^{U}-\beta_{k j}^{L}\right) \frac{\sum_{j=1}^{N} y_{k j}{ }^{(t)}}{h_{k}}
$$

With respect to the following decision variables (assuming $K<M$ and $N$ ):

$$
x_{i k}^{(t)}, y_{k j}{ }^{(t)}, z_{j}{ }^{(t)} \geq 0
$$

In case of a non-cooperative scenario, the multi-objective optimization problem presented by Eq.1.1, and Eq. 1.2, can be rewritten as a compromise programming problem (Para et al. 2005; André and Romero 2008). In this sense, the single objective optimization solutions for individual objectives are identified. The best and worst solutions among them are used to transform the multiobjective optimization problem to a single objective one as follows:

$$
\text { Maximize } \lambda
$$

Subject to the following additional constraints:

$$
\begin{aligned}
& C_{j}^{(T)} \leq \lambda C_{j}^{\text {min }}+(1-\lambda) C_{j}^{\max } \quad j=1,2, \ldots N \\
& H^{(T)} \geq \lambda H^{\text {max }}+(1-\lambda) H^{\text {min }} \\
& 0 \leq \lambda \leq 1
\end{aligned}
$$

Where

$\lambda$ : The compromise variable that captures the possible ranges for each objective function (Decision Variable 2

$C_{j}^{\text {min }}$ : Best (minimum) value of $C_{j}^{(T)}$ in case it is considered as the sole objective function subject to Eqs. 2 to 9.2 and 10 as constraints

$H^{\max }$ : Best (maximum) value of $H^{(T)}$ in case it is considered as the sole objective function subject to Eqs. 2 to 9.2 and 10 as constraints 
$C_{j}^{\text {max }}$ : Worst (maximum) value of $C_{j}^{(T)}$ among all single objective solutions

$H^{\text {min }}$ : Worst (minimum) value of $H^{(T)}$ among all single objective solutions

By maximizing the value of $\lambda$, the best compromise among the objectives is identified, with constraints 12 and 13 capturing the trade-offs among the objectives and ensuring that all objective functions get as close as possible to their optimal values.

The peculiar attribute of the above model rests in the restricted ordering schedules and quantities (due to unavailability of pathways) by advocating nonlinear ordering and distribution costs (to incorporate quantity discount) achieved through multi-level inventories. In this sense, the model has to arrive at the best order quantity within a feasible schedule considering ordering and transportation costs and capacities as well as the perceived collective discounts. In addition, the effect of cooperation in such a supply chain and the conditions that could encourage or discourage them from cooperation will be investigated. In the next section, the proposed model will be applied to a case study of representative northern communities to show its applicability and to gain insights on the impact of bioenergy hubs for dispersed communities in northern Canada, as a means of improving the economies of scale and making the switching to biomass (from diesel) more costefficient.

\section{Case Study}

The case study considers three Quebec northernmost Inuit communities of Kangigsujuaq (KA), Salluit (SA), and Ivujivik (IV) in Nunavik region. These communities are remote and off-grid and located by the Hudson strait. They are currently relying on off-grid diesel facilities for electricity generation, with installed capacities of 1.5, 3, and 1.0 MW (Hydro-Quebec 2008), serving a population of 696, 1347, and 370, respectively (Statistics Canada 2012). Location of these communities is unique from a supply chain perspective as they can only be served by waterways from the east through the Hudson Bay as well as from the west through Labrador Sea (Figure 2).

Establishing biomass as the fuel for electricity generation will benefit these communities from an energy security perspective (through diversifying the energy sources and relying on a 
source (biomass) that is less susceptible to fluctuations in energy prices) and provides them with emission reduction (NRCan, 2015; Laganière et al., 2017). It shall be mentioned that biomass as a fuel is not considered entirely carbon neutral due to emissions involved in preparation and transportation of biomass (Woods et al., 2003; Murphy et al., 2015). In this regard, diesel facilities could serve as backup capacities ensuring an energy production mix for base and peak needs. This fuel diversification plan is challenging as the size of these communities and their remoteness diminishes the economies of scale for biomass supply. The biomass has to come from distant suppliers, where the lack of local sources and the small scale of the supply require a coordinated supply chain network. As such, aggregating the needs of these communities will increase the scale of the supply and will improve the economies of scale. Consequently, ordering one type of biomass (ex. pellets) will be a key factor in improving the cost efficiency through bundling of the orders (received from suppliers) at the hubs. The unique location of these communities provides them with an opportunity to receive biomass supply via two alternative pathways, through Hudson Bay and through Labrador Sea, to benefit from competitive offers at each side and to reduce the risk of shortage. We consider two hubs (one representing each pathway) due to small scale of deliveries. It can be concluded that adding more hubs could diminish the economies of scale at each pathway (lowering the collective quantities handled through each hub).

To achieve the above targets, there is a need for creation of biomass hubs on each side of the supply chain that could serve these communities, and to identify the optimal order quantities and schedules from the suppliers in line with the energy needs of the communities throughout the year and the availability of transportation through the waterways. There would be two alternative coordination scenarios. There is the non-cooperative scenario, in which each community is optimizing its own pay-off and the hubs optimizing their own payoffs as well, and the cooperative option, in which the communities look for a collective solution and are consolidated with the hubs as one entity.

Case study considers two alternative hubs, one in Eastmain $(k=1)$ in the west of Quebec (QC) province and the other one in Bathurst $(k=2)$ in the northeast of New Brunswick (NB) province, representing the two pathways of biomass supply. The hub in NB could receive supplies from three suppliers in QC, NB, and the state of Maine in the US $(i=1,2,3)$, while the hub in Eastmain could receive supplies from three QC suppliers $(i=4,5,6)$. Considering these circumstances, it is assumed that the time between ordering biomass and receiving it at inventories 
is less than one month at both hubs (i.e. orders originated from suppliers) and communities (i.e. orders originated from the hubs). To benefit from the delivery quantity discounts, and to reduce the hassles of arrangements with shipping companies, biomass deliveries are done only in May and August from the ports near the hub locations to the communities. This ordering restriction is also reflecting the normal shipping season in the north (May to August) when the main waterways are free of ice. The information and assumptions about the communities, hubs, and suppliers are summarized in Tables 1 to 5 .

In this regard, properties of biomass (wood pellets) and conversion facilities are approximated from the literature including biomass-to-electricity levelized costs, loading factor, and conversion rates for electricity generation facilities that use pellets (Nasiri and Huang 2008, NEB 2017, IRENA 2018). A planning horizon of one year is considered to enable development of an annual energy production plan. The monthly energy demand (equivalent to 720 hours) values are derived from the latest annual demand profiles reported for these communities (Hydro-Quebec 2002) and the latest average monthly trends reported by Statistics Canada (Statistics Canada 2016), assuming that the per capita electricity demand has not changed considerably during this time (reflecting the population and climate stability).

The hubs to community delivery costs and time are estimated based on the schedule and rates provided by Nunavik Eastern Arctic Shipping Inc. (NEAS 2018a, 2018b). The biomass (bulk pellet) purchase and delivery prices are assumed based on a survey of market prices offered from various pellet suppliers in QC, NB, and the US, reflecting the fact that the supply pathway from Hudson Bay requires longer road transport to Eastmain. It is initially assumed that each community aims at installing a $500 \mathrm{KW}$ biomass-to-electricity conversion facility with their levelized capital and operational costs included in the model (Independent Electricity System Operator (IESO) 2017).

In the next section, the solutions obtained from the proposed model under cooperative and non-cooperative coordination scenarios will be obtained and interpreted in line with the above inputs and assumptions. The ultimate aim would be to investigate the impact of quantity discounts and hub coordination on biomass uptake (\% of electricity from biomass) by these communities and to provide a comparison with the existing all diesel option in terms of the unit costs incurred by the communities individually and collectively. 


\section{Results Analysis}

In this section, we first discuss some characteristics of the proposed model. Then, we turn to interpretation of the results related to each coordination scenario. Further insights will be provided on the effect of hubs as well as suppliers' quantity discounts. Finally, a comparison of the outcomes of alternative supply chain pathways will be provided with respect to cost and share of biomass.

The model was optimized using the latest OpenSolver version 2.9.0 (OpenSolver 2018), with NOMAD (Nonlinear Optimization by Mesh Adaptive Direct Search) (NOMAD 2018). This optimizer is well suited with nonlinear models having more constraints and lesser number of variables. The case study deals with 180 variables and 300 constraints (including additional constraints to reflect the fact about no hub-community deliveries outside May and August months). With an active delivery season running from May to August, the start of the planning year is set at the month of April. In the cooperative scenario, the aggregated supply chain and production costs (collectively coordinated for the communities) are minimized, with purchasing, delivering, and storing decisions to sustain electricity production from biomass during the year. In the noncooperative scenario, the hub acts as an entity maximizing its pay-off (gains from selling biomass to communities minus aggregated sourcing and hub storage costs). Each individual community is minimizing its own cost that corresponds to biomass ordering and storage as well as energy production activities at each community. The later scenario presents a multi-objective optimization problem. By adopting a compromise programming approach, each objective function (community costs and hub payoffs) is optimized subject to the model constraints. Table 6 presents the outcomes of these single objective optimizations showing the conflicts among them. From that table the best and worst values of the objective functions are fed into the compromise program presented through Eqs. 11-14 and subject to all other constraints of the model. By maximizing the value of the compromise index $(\lambda)$, each objective function will approach its best value as far as the feasible region of the problem allows.

Tables 7 to 12 present a summary of the obtained optimal solutions for each coordination scenario, including quantity and schedule of deliveries from suppliers, inventory levels at hubs, quantity and schedule of deliveries to communities, local inventory levels, and electricity production from biomass. As the results show, at the presence of hubs, the supplier capacities can be fully exhausted, arriving at the highest supplier quantity discounts. The hub inventories start to 
accumulate from April with a full dispatch in May, followed by another round of accumulation until the second full dispatch in August. Generation of electricity from biomass commences in May with steady production until December when the biomass inventories decline and gradually come to an end without a chance for re-stocking due to unavailability of waterways.

To demonstrate the role of quantity discounts and the existence of hubs in promoting the share of biomass in electricity generation and in improving the economies of scale, the coordination models have been optimized under a combination of hub coordination and quantity discount scenarios as listed in Table 13. The total cost of energy production, its unit cost (as a measure of the economies of scale), and the share of biomass in electricity generation mix are presented under these scenarios. The unit cost $(\$ / \mathrm{KWh})$ is calculated by distributing the total cost of each scenario (\$) to total electricity generated (KWh) from biomass and diesel sources over the scope of the study (one year).

In the non-cooperative case, the aim of each community to arrive at a minimum cost triggers a competition among communities. Thus, the main operational difference between the cooperative and non-cooperative coordination cases is that, in the former case, both biomass ordering and delivery from hubs are collectively coordinated, while in the latter case, only deliveries from hubs are collective and the orders are received by hubs from the communities independently. In this sense, the communities will lose the opportunity of receiving collective discounts for ordering from the hubs. This creates a chain of effects from the communities to the suppliers. Suppliers 4, 5, and 6, that offer a higher price (as per Table 5) supplying to hub 2 (reflecting a more costly transportation pathway), will receive lower demands in the non-cooperative case (as presented in Table 7). As a result, the capability of hub 2 in accumulation of biomass is compromised causing lower inventory levels for this hub (Table 9). This in turn will affect not only the extent of deliveries arriving from hub 2 but also the number of times deliveries are taking place (Table 10) as well as the cost of deliveries (Table 11). In this situation, the communities will place a higher emphasis on hub 1 to an extent that the community of IV $(j=3)$ will not receive any deliveries from the hub 2 in located New Brunswick. As such, the share of biomass will be reduced in the non-cooperative scenarios compared to their cooperative case as presented in Table 13.

The optimal solutions, obtained with quantity discounts and hubs for each coordination case, are presented in Table 13. In the cooperative case, there will be a $61 \%$ share for biomass and 
a unit cost of $\$ 172$ for each MWh of electricity generated, almost $20 \%$ less than a diesel only solution (i.e. $z_{j}{ }^{(t)}=0$ ) that yields a unit cost of $\$ 212$ per MWh. In the non-cooperative case, smaller communities will benefit more from the coordination of deliveries (even with no collective ordering). This is reflecting fact that smaller communities are dealing with lower demand for electricity, and as such, any amount of delivered biomass could have a bigger impact on their energy production mix. Overall, biomass will still remain a competitive option versus the diesel. The share of biomass ranges from $34.9 \%$ to $54.7 \%$ reflected by the variations in the unit costs from $\$ 157$ to $\$ 178$ per MWh of generated electricity.

Without supplier quantity discounts (i.e. $p_{i k}{ }^{(t)}=p_{i}^{U}$ ), the supply of biomass to communities via hubs will continue but with a slightly higher overall unit cost leading to a similar share for biomass in the electricity mix in both coordination scenarios. With no collective inventories at hubs (i.e. $I_{j}^{(t)}=0$ ), the share of the biomass in the electricity mix in both coordination scenarios will be significantly reduced, as the lack of big inventories (buffers) with the presence of a restricted schedule for biomass deliveries to communities, diminishes the quantities of deliveries leading to only short lived biomass production periods right after the deliveries in May and August, with much higher unit costs. As the results in Table 13 reveals, smaller communities will be in a better position if they opt for non-cooperative coordination as even small deliveries of biomass could form a considerable share of their electricity mix. Despite the above fact, the overall contribution of biomass into the generation of electricity in these communities will be reduced (as presented in Table 12). The case of no inventories at hubs is further considered in case of eliminating the supplier quantity discounts (i.e. $I_{j}{ }^{(t)}=0$ and $p_{i k}{ }^{(t)}=$ $p_{i}^{U}$ ), resulting in a similarly low share for biomass in both coordination scenarios. With no hub inventories, the unit cost will be lower in the cooperative case with supplier discounts at $\$ 197$ per MWh and increases to $\$ 201$ per MWh in the case with no supplier discounts. In summary, the smaller communities will not be motivated to take part in a cooperative coordination and prefer a non-cooperative coordination. The latter scheme is still a means of coordination, reflecting the fact that communities do not prefer to cooperate but prefer to work with a hub that coordinates the supply (through collective inventory) of biomass. No community will have the incentive to deviate from participation in such a non-cooperative hub-based coordination. 
The final case (of no discount and no inventories at hubs), against a backdrop of some uncertainties in biomass supply chains (such as availability, quality, and durability issues of biomass), reflects the current situation with many northern communities, and has discouraged them from adopting biomass electricity generation capacities. The above results demonstrate that the incorporation of hubs in biomass supply chains, serving northern communities, can address the availability issue and improve the economies of scale such that biomass can have a considerable share in electricity profile of these communities. However, to ensure that biomass becomes the dominant fuel for electricity generation in the north, a cooperative coordination pathway is required, where the communities join forces to support collective orders and deliveries. To motivate a cooperative scheme among the communities, external incentives by the government or power companies might be required.

\section{Discussion}

A key aspect of the above results was the finding that all four biomass scenarios in both coordination cases lead to a reduction in the unit cost of energy generation. Therefore, even in scenarios where biomass is not the dominant fuel for energy generation, a cost reduction is still achieved. The cost efficiencies are significantly increased in the scenarios where biomass is the dominant fuel. Therefore, for these remote communities, the addition of biomass as a complementary source of energy implies that a dual desirable outcome of cost efficiency and reduced negative environmental impacts can be achieved. Clearly the availability of discounts and the use of storage hubs are important to improving cost efficiencies and the potential for other incentives from government may further improve the efficiencies achieved.

Despite no direct incentive envisioned from the government for biomass-to-electricity conversion in these communities, the study observed the effect of biomass hubs in consolidating a collective (larger scale) biomass supply. With hubs, a remarkable reduction in unit cost of biomassto-electricity conversion is achieved as demonstrated in Table 3 (due to higher supplier discounts for coordinated orders). The scenarios with hub involvement (coordination) correspond to up to $20 \%$ reduction in the unit costs. This is due to the effect of the economies of scale. With a small scale of electricity generation in these communities, without the hubs (and coordination) in place, 
the share of biomass in electricity mix could be as low as $21 \%$ (Table 3 ) and diesel remains as the dominating fuel. With hubs (coordination), this share could increase up to $61 \%$. In non-cooperative coordination scenarios, hub's coordination will result in a compromise between hub's profit (objective) and individual communities' cost (objectives). Thus, in this case, the hub has to accept a compromise on its profit in order to allow for the communities to achieve cost efficiency in preferring biomass to diesel.

While this study was based on the case of northern communities in Canada, the findings provide strong indications for the use of biomass in other parts of the world. The provision of grid power can be expensive or technically complex to communities in difficult geographical locations where weather-based factors such as snow and topographical-based factors such as mountains and rivers/swamps dominate. Such complexities are further pronounced if the communities are small and relatively dispersed. The potential to adopt biomass as a complement or replacement to any current sources of energy provide a significant opportunity for better efficiencies. The ability to store biomass material not only implies the potential to eliminate the need for continuous delivery to such difficult geographical locations but also boosts energy security and can have a strong positive impact on quality of life. This transition could also promote institutional change in energy industry fostering new regulations and management practices (Genus and Mafakheri 2014).

In summary, the viability of biomass as a main or complementary source of energy for remote communities will need to be considered on a case-by-case basis taking into account various factors such as supply chain networks, unique geographical characteristics, community acceptance, current power generation attributes, availability and type of biomass amongst others (De Meyer et al. 2015). The locations of the two hubs in QC and NB were carefully chosen to represent the only alternative supply chain pathways through Hudson Bay and Labrador Sea. These hubs are located further from the communities, encouraging suppliers to work with these hubs, as the major share of transportation costs will not be borne by them. The choice of suppliers in QC, NB, and the state of Maine in the US was decided based on the feasibility of supply to the hubs in Quebec and New Brunswick. The adopted biomass prices reflect this geographical-based choice as well as suppliers' scale of production and closeness to biomass sources. If the choices of suppliers change, or if biomass is advocated for a different geography, the model might end up with different results, however, the same model can be adopted for decision making. 
As for biomass, fuel prices are showing more stability and are not subject to fluctuations in the wider energy market prices, conducting a sensitivity analysis on diesel prices would be a valuable contribution. However, as this study has adopted a levelized costing of electricity generation (for both diesel and biomass) to reflect on a long-term commitment to diversification of energy sources, the proposed model cannot capture the effect of short-term fluctuations in diesel prices. In this regard, however, it is worth mentioning that biomass (and diesel) deliveries to communities is done only a few times a year based on agreed price ranges and discounting mechanism preceding the deliveries. This reduces the ability of communities to have sudden impacts from changes in diesel prices. Diesel is also purchased well ahead of time and stored for a longer period of time in these communities.

It should be mentioned that suppliers' selling prices will be lowered with the coordination in place. However, this is reflective of the quantity discounts on offer. The suppliers offered a range of acceptable prices for coordinated purchase. The coordination gradually directs the prices towards the lower bound of this range. This is not desirable for suppliers, but in return, lower prices increases the quantity of biomass sale.

This study has important implications for society and research. For the northern communities in Canada and for other similar communities, there is an urgent need to explore the potential of biomass as a potential main source of energy. The availability of biomass material and the ability to store them suggests than not only can power be generated at a lower cost, but it can be done in an environmentally friendly manner. For industry producers of biomass material, the study highlights the availability of potential new markets that may be viable even when situated in geographical locations with access limitations. For government, there is the potential to reduce emissions generation by supporting, promoting and possibly providing incentives for the use of biomass as an alternative source of energy in communities that are too geographically remote to be connected to the main grid. It shall be mentioned that the cost is rationally assumed to be the main factor in deciding about the choice of energy sources for northern communities. However, if some users want to opt for non-bioenergy options, such as installing small scale wind or solar technologies, their needs shall be subtracted from the demand predictions used as inputs for the model. That will decrease the economies of scale for a community-wide bioenergy generation. 


\section{Conclusions}

This study presented a supply chain modelling approach to formulate the case of electricity generation from biomass in off-grid northern communities as an alternative to diesel. The cooperative and non-cooperative coordination scenarios among these communities were presented through collective and multi-objective optimization problems, respectively. The incorporation of coordinated biomass hubs and quantity discounts were advocated demonstrating their potential in improving the economies of scale in electricity generation. Such a diversification of energy sources is of particular importance to northern communities, improving their resilience as well as reducing their carbon emission generation. Due to higher prices of diesel in the north, biomass could assume a higher share of the market even without a direct incentive from the Government. The case of three off-grid communities in Nunavik was considered, potentially receiving biomass supplies via alternative waterways in the absence of road networks. The results pointed to the significant role of hubs in creating coordinated buffer capacities that could ensure a sustained production of electricity from biomass with the presence of quantity discounts. The price reduction that results would be beneficial to the local economy of these remote parts of Canada.

This study could be further extended in many ways. First, a supplier selection system could be coupled with the proposed model to rank the suppliers according to a number of prequalification criteria, and on that basis, prioritize the order quantities (Mafakheri et al. 2011). In addition, the durability of biomass materials could be incorporated into the model by assuming a decay rate for them. Such decays particularly diminish the local inventories steadily throughout the year. The possibility of using varied biomass materials could be considered as a way of extending the supply capacities and further increasing the share of biomass in off-grid electricity generation in the north. The monthly generation plans could be translated into hourly generation schedules by coupling the proposed model with an operational model of electricity generation facilities in daily peak and base periods. The impact of a direct or indirect government incentive for bioenergy production in the north could be considered. The incentive could be an indirect one, in form of an emission regulatory mechanism (Palak et al. 2014), or could be a direct benefit allocated per KWh of electricity generated from biomass (Nasiri and Zaccour 2010). In both cases, the incentive will compensate the supply chain and production costs of bioenergy generation. The main benefit of such an incentive would be in creation of a surge towards investing in bioenergy generation. The main 
drawback would be the fact that, with the existence of an incentive, producers might opt for less cost-efficient bioenergy generation technologies creating a lasting dependency to an incentive (Grant and Clarke 2010).

The environmental costs associated with energy generation could also be incorporated into the model in form of a penalty or pollution constraints. This could further incentivize biomass over diesel. In addition, the competition among suppliers could also be formulated through a bi-level model. In the lower level model, the optimal biomass electricity generation capacities and plans are identified. In the upper level model, the suppliers will compete to fulfil the energy generation plan. In addition, a location analysis model (Rentizelas and Tatsiopoulos 2010) could be linked to the proposed model such that the location and number of hubs could be optimally identified among the possible choices considering their distances and subsequent delivery costs.

\section{Acknowledgement}

We are grateful to three anonymous reviewers for their reviews and comments, which were very helpful in improving the quality of the manuscript. This study has been funded through a Discovery grant from Natural Sciences and Engineering Research Council (NSERC) of Canada, reference number: RGPIN-2019-07086.

\section{References}

Alaei, Saeed, and Mostafa Setak. "Multi objective coordination of a supply chain with routing and service level consideration." International Journal of Production Economics 167 (2015): 271281.

André, Francisco J., and C. Romero. "Computing compromise solutions: On the connections between compromise programming and composite programming." Applied Mathematics and Computation 195, no. 1 (2008): 1-10.

Cai, Jianhu, Xiaoqing $\mathrm{Hu}$, Ke Chen, Pandu R. Tadikamalla, and Jennifer Shang. "Supply chain coordination under production yield loss and downside risk aversion." Computers \& Industrial Engineering 127 (2019): 353-365. 
CanBio. "Report on the Status of Bioenergy in Canada", Canadian Bioenergy Association (CanBio), Ottawa (2014).

Chaharsooghi, S. Kamal, and Jafar Heydari. "Supply chain coordination for the joint determination of order quantity and reorder point using credit option." European Journal of Operational Research 204, no. 1 (2010): 86-95.

Chan, Hau-Ling. "Supply chain coordination with inventory and pricing decisions." International Journal of Inventory Research 5, no. 3 (2019): 234-250.

De Meyer, Annelies, Dirk Cattrysse, and Jos Van Orshoven. "A generic mathematical model to optimise strategic and tactical decisions in biomass-based supply chains (OPTIMASS)." European Journal of Operational Research 245, no. 1 (2015): 247-264.

Ellabban, Omar, Haitham Abu-Rub, and Frede Blaabjerg. "Renewable energy resources: Current status, future prospects and their enabling technology." Renewable and Sustainable Energy Reviews 39 (2014): 748-764. Ganeshan, Ram. "Managing supply chain inventories: A multiple retailer, one warehouse, multiple supplier model." International Journal of Production Economics 59, no. 1-3 (1999): 341-354.

Genus, Audley, and Fereshteh Mafakheri. "A neo-institutional perspective of supply chains and energy security: bioenergy in the UK." Applied energy 123 (2014): 307-315.

Giri, Bibhas Chandra, and Sudarshan Bardhan. "Coordinating a supply chain under uncertain demand and random yield in presence of supply disruption." International Journal of Production Research 53, no. 16 (2015): 5070-5084.

Grant, N., \& Clarke, A. "Biomass-a burning issue." The Association for Environment Conscious Building (AECB), Llandysul, UK (2010).

Heydari, Jafar. "Supply chain coordination using time-based temporary price discounts." Computers \& Industrial Engineering 75 (2014): 96-101.

Hou, Yumei, Fangfang Wei, Susan X. Li, Zhimin Huang, and Allan Ashley. "Coordination and performance analysis for a three-echelon supply chain with a revenue sharing contract." International Journal of Production Research 55, no. 1 (2017): 202-227.

Huang, Yeu-Shiang, Rong-Shuan Ho, and Chih-Chiang Fang. "Quantity discount coordination for allocation of purchase orders in supply chains with multiple suppliers." International Journal of Production Research 53, no. 22 (2015): 6653-6671. 
Hydro-Quebec. «PARTICULARITÉS DES RÉSEAUX AUTONOMES » (Demande R-34922002), Hydro-Québec Distribution, Régie de l'énergie du Québec, Montreal, QC (2002).

Hydro-Quebec. «Plan d'approvisionnement 2008-2017 des réseaux autonomes - Annexes » (Docket R-3648-2007, HQD-2, Document 2). Hydro-Québec Distribution, Régie de l'énergie du Québec, Montreal, QC (2008).

IESO. "FIT Price Schedule." Independent Electricity System Operator (IESO), Toronto, ON (2017).

IRENA, IREA. "Renewable power generation costs in 2017." Report, International Renewable Energy Agency, Abu Dhabi, UAE (2018).

Laganière, J.; Paré, D.; Thiffault, E.; Bernier, P. Y. "Range and uncertainties in estimating delays in greenhouse gas mitigation potential of forest bioenergy sourced from Canadian forests." $G C B$ Bioenergy 9 (2017): 358-369.

Mafakheri, Fereshteh, Michele Breton, and Ahmed Ghoniem. "Supplier selection-order allocation: A two-stage multiple criteria dynamic programming approach." International Journal of Production Economics 132, no. 1 (2011): 52-57.

Mafakheri, Fereshteh, and Fuzhan Nasiri. "Revenue sharing coordination in reverse logistics." Journal of Cleaner Production 59 (2013): 185-196.

Mafakheri, Fereshteh, and Fuzhan Nasiri. "Modeling of biomass-to-energy supply chain operations: Applications, challenges and research directions." Energy Policy 67 (2014): 116126.

Mena, Carlos, Andrew Humphries, and Thomas Y. Choi. "Toward a theory of multi-tier supply chain management." Journal of Supply Chain Management 49, no. 2 (2013): 58-77.

Minner, Stefan. "Multiple-supplier inventory models in supply chain management: A review." International Journal of Production Economics 81 (2003): 265-279.

Miranda, Teresa, Irene Montero, Francisco Sepúlveda, José Arranz, Carmen Rojas, and Sergio Nogales. "A review of pellets from different sources." Materials 8, no. 4 (2015): 1413-1427.

Nasiri, F., and G. Huang. "Integrated capacity planning for electricity generation: a fuzzy environmental policy analysis approach." Energy Sources, Part B 3, no. 3 (2008): 259-279.

Nasiri, Fuzhan, and Georges Zaccour. "Renewable portfolio standard policy: a game-theoretic analysis." INFOR: Information Systems and Operational Research 48, no. 4 (2010): 251-260. 
Nasiri, Fuzhan, Fereshteh Mafakheri, Dotun Adebanjo, and Fariborz Haghighat. "Modeling and analysis of renewable heat integration into non-domestic buildings-The case of biomass boilers: A whole life asset-supply chain management approach." Biomass and bioenergy 95 (2016): 244-256.

NEAS. "Nunavik Sealift Rates for 2018 Season.” Nunavik Eastern Arctic Shipping Inc. (2018a): https://neas.ca/wp-content/uploads/freight_nunavik.pdf (accessed on Sept. 10, 2019)

NEAS. "Sailing Schedule.” Nunavik Eastern Arctic Shipping Inc. (2018b): https://neas.ca/wpcontent/uploads/sailing_schedule.pdf (accessed on Sept. 10, 2019)

NEB. “Canada's Energy Future 2016: Energy Supply and Demand Projections to 2040”, National Energy Board, Canada, Cat. No. NE2-12/2015E (2016).

NEB. "Canada's Adoption of Renewable Power Sources: Energy Market Analysis." National Energy Board, Calgary, AB, Canada (2017).

Neupane, B., Halog, A., \& Lilieholm, R. J. "Environmental sustainability of wood-derived ethanol: a life cycle evaluation of resource intensity and emissions in Maine, USA." Journal of Cleaner Production, 44 (2013): 77-84.

NOMAD. "Nonlinear Optimization by Mesh Adaptive Direct Search (NOMAD)." Groupe d'études et de recherche en analyse des decisions (GERAD) (2018): https://www.gerad.ca/nomad/ (accessed on Sept. 10, 2019).

NRCan. "Status of remote/off-grid communities in Canada", Report \# M154-71/2013E, ISBN: 978-1-100-22428-2. Natural Resources Canada. Ottawa, ON (2011).

NRCan. "Bioenergy GHG calculator", Natural Resources Canada. Ottawa, ON (2015): https://apps-scf-cfs.rncan.gc.ca/calc/en/bioenergy-calculator (last accessed: March 28, 2020).

Oliveira, Fernando S., Carlos Ruiz, and Antonio J. Conejo. "Contract design and supply chain coordination in the electricity industry." European Journal of Operational Research 227, no. 3 (2013): 527-537.

OpenSolver. "The OpenSolver version 2.9.0” (2018): https://opensolver.org/ (accessed on Sept. 10, 2019).

Palak, Gökçe, Sandra Duni Ekşioğlu, and Joseph Geunes. "Analyzing the impacts of carbon regulatory mechanisms on supplier and mode selection decisions: An application to a biofuel supply chain." International Journal of Production Economics 154 (2014): 198-216. 
Parra, M. Arenas, A. Bilbao Terol, B. Pérez Gladish, and MV Rodríguez Uría. "Solving a multiobjective possibilistic problem through compromise programming." European Journal of Operational Research 164, no. 3 (2005): 748-759.

Paré, David, Pierre Bernier, Evelyne Thiffault, and Brian D. Titus. "The potential of forest biomass as an energy supply for Canada." The Forestry Chronicle 87, no. 1 (2011): 71-76.

Rahman, R. "Feasibility analysis of wood-biomass energy generation for the off-grid community of Brochet in North-west Manitoba", MB, Canada (2014).

Rentizelas, Athanasios A., Athanasios J. Tolis, and Ilias P. Tatsiopoulos. "Logistics issues of biomass: The storage problem and the multi-biomass supply chain." Renewable and sustainable energy reviews 13, no. 4 (2009): 887-894.

Rentizelas, Athanasios A., and Ilias P. Tatsiopoulos. "Locating a bioenergy facility using a hybrid optimization method." International Journal of Production Economics 123, no. 1 (2010): 196209.

Sarkar, S., Kumar, A., \& Sultana, A. "Biofuels and biochemicals production from forest biomass in Western Canada." Energy, 36, no. 10 (2011): 6251-6262.

Sarkar, Biswajit. "Supply chain coordination with variable backorder, inspections, and discount policy for fixed lifetime products." Mathematical Problems in Engineering 2016 (2016).

Shahabi, Mehrdad, Shirin Akbarinasaji, Avinash Unnikrishnan, and Rachel James. "Integrated inventory control and facility location decisions in a multi-echelon supply chain network with hubs." Networks and Spatial Economics 13, no. 4 (2013): 497-514.

Statistics Canada. “Census profiles: Census 2011”, Statistics Canada, Ottawa, ON (2012).

Statistics Canada. "Electric power statistics: 2015", Statistics Canada, Ottawa, ON (2016).

Sun, Fangzhou, Maichel M. Aguayo, Rahul Ramachandran, and Subhash C. Sarin. "Biomass feedstock supply chain design-a taxonomic review and a decomposition-based methodology." International Journal of Production Research 56, no. 17 (2018): 5626-5659.

Tong, Jordan, Gregory DeCroix, and Jing-Sheng Song. "Modeling payment timing in multiechelon inventory systems with applications to supply chain coordination." Manufacturing \& Service Operations Management (2019), accepted-in press.

Yazan, Devrim Murat, A. Claudio Garavelli, Antonio Messeni Petruzzelli, and Vito Albino. "The effect of spatial variables on the economic and environmental performance of bioenergy production chains." International journal of production economics 131, no. 1 (2011): 224-233. 
Zandi Atashbar, Nasim, Nacima Labadie, and Christian Prins. "Modelling and optimisation of biomass supply chains: a review." International Journal of Production Research 56, no. 10 (2018): 3482-3506.

Zhang, Qinhong, Ming Dong, Jianwen Luo, and Anders Segerstedt. "Supply chain coordination with trade credit and quantity discount incorporating default risk." International Journal of Production Economics 153 (2014): 352-360. 


\section{List of Symbols}

Suppliers: $i=1,2, \ldots M$;

Communities: $j=1,2, \ldots N$;

Hubs: $k=1,2, \ldots K$;

$p_{i k}{ }^{(t)}$ : Biomass price (including transportation) offered by supplier ' $i$ ' for delivery to hub centre ' $k$ ' at time ' $t$ ' $(\$ / \mathrm{Kg})$

$x_{i k}{ }^{(t)}$ : Biomass delivery from supplier ' $i$ ' to hub centre ' $k$ ' at time ' $t$ ' $(\mathrm{Kg})$ : Decision Variable $H_{k}$ : Holding cost at hub ' $k$ ' per unit of time $(\$ / \mathrm{Kg})$

$h_{k}{ }^{(t)}$ : Biomass inventory level at hub ' $k$ ' at time ' $t$ ' $(\mathrm{Kg})$

$\beta_{k j}{ }^{(t)}$ : Biomass ordering/delivery cost from hub ' $k$ ' to community ' $j$ ' at time ' $t$ ' $(\$ / K g)$

$y_{k j}{ }^{(t)}$ : Biomass delivery from hub ' $k$ ' to community ' $j$ ' at time ' $t$ ' (Kg): Decision Variable

$\alpha_{j}$ : Holding cost at local biomass inventory of community ‘ $j$ ’ per unit of time $(\$ / \mathrm{Kg})$

$I_{j}{ }^{(t)}$ : Local biomass inventory level at community ' $j$ ' at time ' $t$ ' $(\mathrm{Kg})$

$r_{k j}$ : Delivery time between hub ' $k$ ' and community ' $j$ ' (Month)

$z_{j}^{(t)}$ : Electricity generation from biomass in community ' $j$ ' at time ' $t$ ' $(\mathrm{KWh})$ : Decision Variable

$\gamma_{j}$ : Levelized biomass-to-electricity conversion cost in community ' $j$ ' including capital and operational costs $(\$ / \mathrm{KWh})$

$\delta_{j}$ : Levelized electricity generation cost from alternative (diesel) fuel in facility of community ' $j$ ' at time ' $t$ ' including capital, operational and fuel costs $(\$ / K W h)$

$D_{j}{ }^{(t)}$ : Electricity demand of community ' $j$ ' at time ' $t$ ' $(\mathrm{KWh})$ 
$t_{i k}$ : Delivery time between supplier ' $i$ ' and hub ' $k$ ' (Month)

$f_{j}$ : Biomass conversion rate in biomass-to-electricity conversion facility of community ‘ $j$ ’ $(\mathrm{KWh} / \mathrm{Kg})$

$Z_{j}$ : Capacity of biomass electricity generation facility in community ' $j$ ' $(\mathrm{KW})$

$\theta_{j}$ : Loading factor of biomass electricity generation facility in community ' $j$ ’

$I_{j}$ : Capacity of local biomass inventory at community ' $j$ ’ $(\mathrm{Kg})$

$h_{k}$ : Capacity of hub ' $k$ ' $(\mathrm{Kg})$

$S_{i}$ : Biomass supply capacity of supplier ' $i$ ' $(\mathrm{Kg})$

$p_{i}^{U}$ : Biomass price of supplier ' $i$ ' with no discount $(\$ / \mathrm{Kg})$

$p_{i}^{L}$ : Biomass price of supplier ' $i$ ' with full discount $(\$ / \mathrm{Kg})$

$\beta_{k j}^{U}$ : Biomass order/delivery cost from hub ' $k$ ' to community ' $j$ ' with no discount $(\$ / \mathrm{Kg})$

$\beta_{k j}^{L}$ : Biomass order/delivery cost from hub ' $k$ ' to community ' $j$ ' with full discount $(\$ / \mathrm{Kg})$

$\lambda$ : The compromise variable that captures the possible ranges for each objective function: Decision $\underline{\text { Variable }}$

$C_{j}^{\text {min }}$ : Best (minimum) value of $C_{j}^{(T)}$ in case it is considered as the sole objective function subject to Eqs. 2 to 9.2 and 10 as constraints

$H^{\text {max }}$ : Best (maximum) value of $H^{(T)}$ in case it is considered as the sole objective function subject to Eqs. 2 to 9.2 and 10 as constraints

$C_{j}^{\text {max }}$ : Worst (maximum) value of $C_{j}^{(T)}$ among all single objective solutions

$H^{\min }$ : Worst (minimum) value of $H^{(T)}$ among all single objective solutions 


\section{Figures}

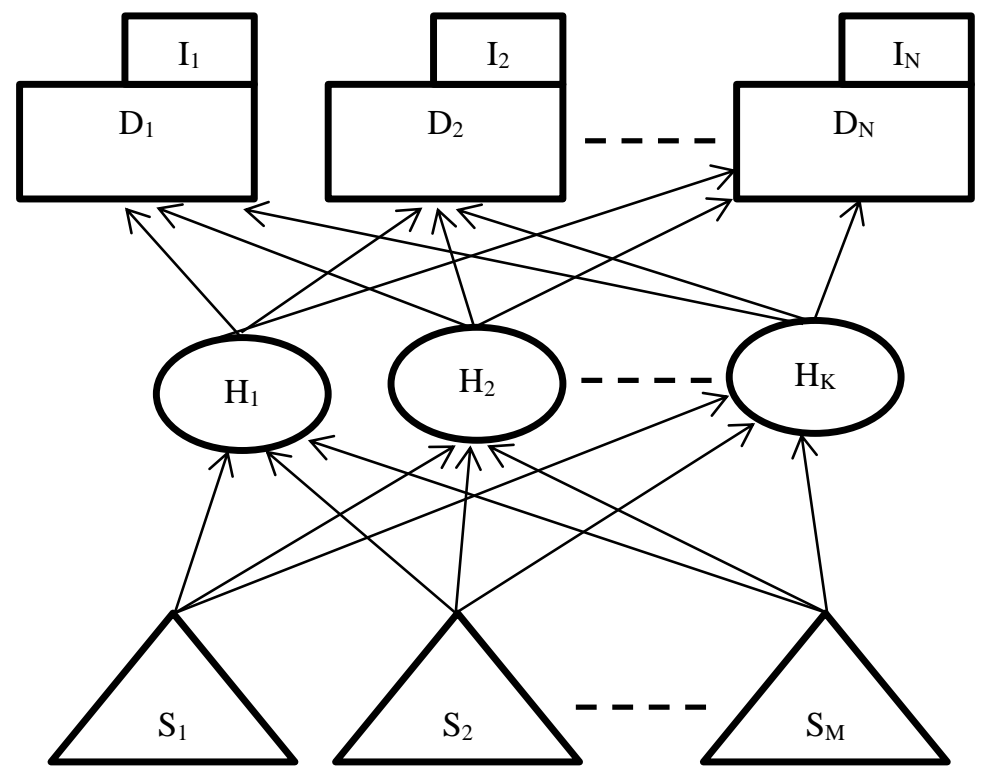

Figure 1 - A supply chain network with suppliers $\left(\mathrm{S}_{1}\right.$ to $\left.M\right)$, hubs $\left(\mathrm{H}_{1}\right.$ to $\left.K\right)$, and community demand $\left(\mathrm{D}_{1}\right.$ to $\left.\mathrm{N}\right)$ and inventories ( $\mathrm{I}_{1}$ to $\left.\mathrm{N}\right)$ 


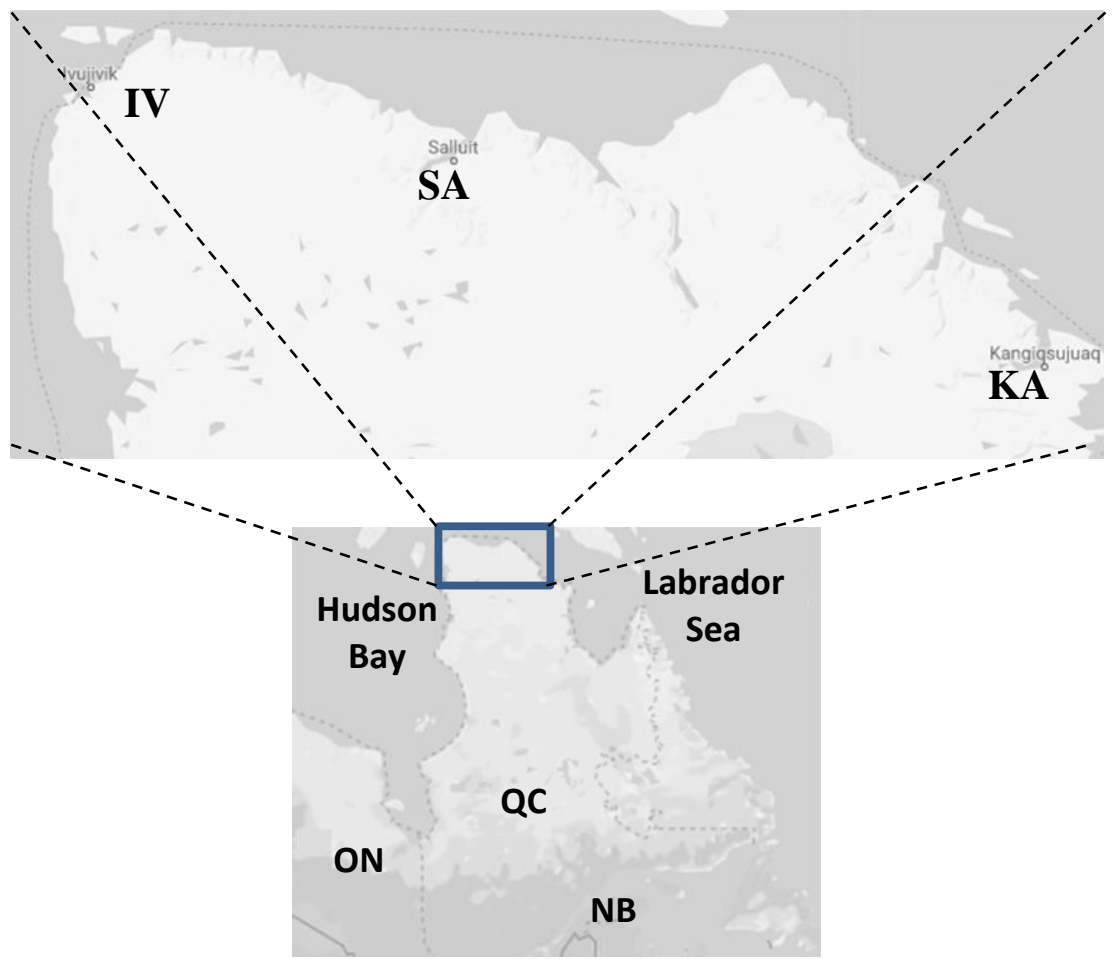

Figure 2 - Case study northern communities of Quebec and their locations 


\section{Tables}

Table 1 - Community-related information and assumptions

\begin{tabular}{|c|c|c|c|}
\hline \multirow{2}{*}{ Parameters } & \multicolumn{3}{|c|}{ Communities } \\
\cline { 2 - 4 } & $\begin{array}{c}\text { KA } \\
(\mathrm{j}=1)\end{array}$ & $\begin{array}{c}\text { SA } \\
(\mathrm{j}=2)\end{array}$ & $\begin{array}{c}\text { IV } \\
(\mathrm{j}=3)\end{array}$ \\
\hline$Z_{j}$ & 500 & 500 & 500 \\
\hline$I_{j}$ & 200,000 & 200,000 & 1500,000 \\
\hline$\alpha_{j}$ & 0.004 & 0.003 & 0.004 \\
\hline$\gamma_{j}$ & 0.046 & 0.044 & 0.048 \\
\hline$\delta_{j}$ & 0.208 & 0.215 & 0.207 \\
\hline$\theta_{j}$ & 0.80 & 0.85 & 0.80 \\
\hline$f_{j}$ & 4.7 & 4.8 & 4.6 \\
\hline
\end{tabular}

Table 2 - Projected community monthly electricity demand $\left(D_{j}{ }^{(t)}\right)$

\begin{tabular}{|l|c|c|c|}
\hline \multirow{2}{*}{ Month } & \multicolumn{3}{|c|}{ Communities } \\
\cline { 2 - 4 } & $\begin{array}{c}\text { KA } \\
(\mathrm{j}=1)\end{array}$ & $\begin{array}{c}\text { SA } \\
(\mathrm{j}=2)\end{array}$ & $\begin{array}{c}\text { IV } \\
(\mathrm{j}=3)\end{array}$ \\
\hline April & 186,300 & 351,500 & 100,500 \\
\hline May & 171,900 & 324,400 & 92,800 \\
\hline June & 171,000 & 322,600 & 92,300 \\
\hline July & 180,900 & 341,200 & 97,600 \\
\hline August & 179,700 & 339,100 & 97,000 \\
\hline September & 168,700 & 318,300 & 91,100 \\
\hline October & 178,700 & 337,100 & 96,400 \\
\hline November & 194,800 & 367,500 & 105,100 \\
\hline December & 216,800 & 409,000 & 117,000 \\
\hline January & 246,900 & 465,900 & 133,300 \\
\hline February & 226,500 & 427,400 & 122,300 \\
\hline March & 219,900 & 414,900 & 118,700 \\
\hline
\end{tabular}

Table 3 - Hubs-related information and assumptions

\begin{tabular}{|c|c|c|}
\hline \multirow{2}{*}{ Parameters } & \multicolumn{2}{|c|}{ Hubs } \\
\cline { 2 - 3 } & $\begin{array}{c}\mathrm{QC} \\
(\mathrm{k}=1)\end{array}$ & $\begin{array}{c}\mathrm{NB} \\
(\mathrm{k}=2)\end{array}$ \\
\hline$H_{k}$ & 350,000 & 400,000 \\
\hline$h_{k}$ & 0.002 & 0.0015 \\
\hline
\end{tabular}


Table 4 - Biomass ordering/delivery cost ranges and time from hubs to communities $\left(\beta_{k j}^{U}, \beta_{k j}^{L}\right)$

\begin{tabular}{|c|c|c|c|}
\hline \multirow{3}{*}{ Hubs } & \multicolumn{3}{|c|}{ Communities } \\
\cline { 2 - 4 } & $\begin{array}{c}\text { KA } \\
(\mathrm{j}=1)\end{array}$ & $\begin{array}{c}\text { SA } \\
(\mathrm{j}=2)\end{array}$ & $\begin{array}{c}\text { IV } \\
(\mathrm{j}=3)\end{array}$ \\
\hline QC & $(0.362,0.235)$ & $(0.362,0.235)$ & $(0.362,0.235)$ \\
$(\mathrm{k}=1)$ & & $(0.409$, & $(0.409$, \\
\hline NB & $(0.409$, & $0.266)$ & $0.266)$ \\
$(\mathrm{k}=2)$ & $0.266)$ & \multicolumn{3}{|c}{} \\
\hline
\end{tabular}

Table 5 - Supplier-related information and assumptions

\begin{tabular}{|c|c|c|c|}
\hline \multirow{2}{*}{$\begin{array}{c}\text { Suppliers } \\
(i)\end{array}$} & \multicolumn{3}{|c|}{ Parameters } \\
\cline { 2 - 4 } & $p_{i}^{U}$ & $p_{i}^{L}$ & $S_{i}$ \\
\hline 1 & 0.205 & 0.168 & 33,300 \\
\hline 2 & 0.210 & 0.170 & 34,000 \\
\hline 3 & 0.200 & 0.175 & 34,700 \\
\hline 4 & 0.215 & 0.190 & 37,000 \\
\hline 5 & 0.220 & 0.190 & 35,000 \\
\hline 6 & 0.220 & 0.185 & 34,000 \\
\hline
\end{tabular}

Table 6 - Single objective optimizations and the resulting values for objective functions

\begin{tabular}{|c|c|c|c|c|}
\hline \multirow{2}{*}{ Optimization } & \multicolumn{4}{|c|}{ Objective Functions } \\
\cline { 2 - 5 } & $\mathrm{C}_{1}{ }^{(\mathrm{T})}$ & $\mathrm{C}_{2}{ }^{(\mathrm{T})}$ & $\mathrm{C}_{3}{ }^{(\mathrm{T})}$ & $\mathrm{H}^{(\mathrm{T})}$ \\
\hline${\text { Min } \mathrm{C}_{1}{ }^{(\mathrm{T})}}^{\mathbf{3 i n} \mathrm{C}_{2}{ }^{(\mathrm{T})}}$ & $\mathbf{3 2 5 , 3 0 0}$ & 950,064 & 261,669 & 41,050 \\
\hline $\operatorname{Min}_{3}{ }^{(\mathrm{T})}$ & 487,157 & $\mathbf{7 0 4 , 6 2 2}$ & 261,669 & 47,663 \\
\hline $\operatorname{Max~H}^{(\mathrm{T})}$ & 487,157 & 950,064 & $\mathbf{1 6 6 , 3 2 2}$ & 32,471 \\
\hline
\end{tabular}

Table 7 - Supplier deliveries $\left(x_{i k}{ }^{(t)}\right)$ under cooperative $(\mathrm{CO})$ and non-cooperative (NC) scenarios

\begin{tabular}{|c|c|c|c|c|c|c|c|c|c|c|c|c|}
\hline \multirow[t]{3}{*}{ Month } & \multicolumn{6}{|c|}{$\mathrm{k}=1$} & \multicolumn{6}{|c|}{$\mathrm{k}=2$} \\
\hline & \multicolumn{2}{|c|}{$\mathrm{i}=1$} & \multicolumn{2}{|c|}{$\mathrm{i}=2$} & \multicolumn{2}{|c|}{$\mathrm{i}=3$} & \multicolumn{2}{|c|}{$i=4$} & \multicolumn{2}{|c|}{$i=5$} & \multicolumn{2}{|c|}{$i=6$} \\
\hline & $\mathrm{CO}$ & $\mathrm{NC}$ & $\mathrm{CO}$ & $\mathrm{NC}$ & $\mathrm{CO}$ & $\mathrm{NC}$ & $\mathrm{CO}$ & $\mathrm{NC}$ & $\mathrm{CO}$ & $\mathrm{NC}$ & $\mathrm{CO}$ & $\mathrm{NC}$ \\
\hline April & 3,300 & 33,300 & 34,000 & 34,000 & 34,700 & 34,700 & 34,224 & 13,003 & 35,000 & 35,000 & 34,000 & 17,000 \\
\hline May & 3,300 & 33,300 & 34,000 & 34,000 & 34,700 & 34,700 & 37,000 & 37,000 & 35,000 & 35,000 & 34,000 & 34,000 \\
\hline June & 3,300 & 33,300 & 34,000 & 34,000 & 34,700 & 34,700 & 37,000 & 0 & 35,000 & 2,014 & 34,000 & 517 \\
\hline July & 33,300 & 33,300 & 34,000 & 34,000 & 34,700 & 34,700 & 37,000 & 488 & 35,000 & 0 & 34,000 & 783 \\
\hline Augus & 33,300 & 33,300 & 34,000 & 34,000 & 34,700 & 34,700 & 37,000 & 37,000 & 35,000 & 35,000 & 34,000 & 34,000 \\
\hline
\end{tabular}


Table 8 - Supplier prices $\left(p_{i k}{ }^{(t)}\right)$ under CO and NC scenarios

\begin{tabular}{|l|c|c|c|c|c|c|c|c|c|c|c|c|}
\hline \multirow{3}{*}{ Month } & \multicolumn{9}{|c|}{$\mathrm{k}=1$} & \multicolumn{9}{c|}{$\mathrm{k}=2$} \\
\cline { 2 - 13 } & \multicolumn{2}{|c|}{$\mathrm{i}=1$} & \multicolumn{2}{c|}{$\mathrm{i}=2$} & \multicolumn{2}{c|}{$\mathrm{i}=3$} & \multicolumn{2}{c|}{$\mathrm{i}=4$} & \multicolumn{2}{c|}{$\mathrm{i}=5$} & \multicolumn{2}{c|}{$\mathrm{i}=6$} \\
\cline { 2 - 13 } & $\mathrm{CO}$ & $\mathrm{NC}$ & $\mathrm{CO}$ & $\mathrm{NC}$ & $\mathrm{CO}$ & $\mathrm{NC}$ & $\mathrm{CO}$ & $\mathrm{NC}$ & $\mathrm{CO}$ & $\mathrm{NC}$ & $\mathrm{CO}$ & $\mathrm{NC}$ \\
\hline April & 0.168 & 0.168 & 0.170 & 0.170 & 0.175 & 0.175 & 0.192 & 0.206 & 0.190 & 0.190 & 0.185 & 0.203 \\
\hline May & 0.168 & 0.168 & 0.170 & 0.170 & 0.175 & 0.175 & 0.190 & 0.190 & 0.190 & 0.190 & 0.185 & 0.185 \\
\hline June & 0.168 & 0.168 & 0.170 & 0.170 & 0.175 & 0.175 & 0.190 & 0.215 & 0.190 & 0.218 & 0.185 & 0.219 \\
\hline July & 0.168 & 0.168 & 0.170 & 0.170 & 0.175 & 0.175 & 0.190 & 0.215 & 0.190 & 0.220 & 0.185 & 0.219 \\
\hline August & 0.168 & 0.168 & 0.170 & 0.170 & 0.175 & 0.175 & 0.190 & 0.190 & 0.190 & 0.190 & 0.185 & 0.185 \\
\hline
\end{tabular}

Table 9 - Inventory level at hubs $\left(h_{k}{ }^{(t)}\right)$ under CO and NC scenarios

\begin{tabular}{|l|c|c|c|c|}
\hline \multirow{2}{*}{ Month } & \multicolumn{2}{|c|}{$\mathrm{k}=1$} & \multicolumn{2}{c|}{$\mathrm{k}=2$} \\
\cline { 2 - 5 } & $\mathrm{CO}$ & $\mathrm{NC}$ & $\mathrm{CO}$ & $\mathrm{NC}$ \\
\hline April & 102,000 & 102,000 & 103,224 & 65,003 \\
\hline May & 0 & 0 & 49,071 & 0 \\
\hline June & 102,000 & 102,000 & 155,071 & 2,582 \\
\hline July & 204,000 & 204,000 & 261,071 & 1,271 \\
\hline August & 0 & 0 & 0 & 0 \\
\hline
\end{tabular}

Table 10 - Delivery quantity from hubs to communities $\left(y_{k j}{ }^{(t)}\right)$ under $\mathrm{CO}$ and NC scenarios

\begin{tabular}{|c|c|c|c|c|c|c|c|c|c|c|c|c|}
\hline \multirow{3}{*}{ Month } & \multicolumn{6}{|c|}{$\mathrm{k}=1$} & \multicolumn{6}{|c|}{$\mathrm{k}=2$} \\
\hline & \multicolumn{2}{|c|}{$\begin{array}{c}\mathrm{KA} \\
(\mathrm{j}=1)\end{array}$} & \multicolumn{2}{|c|}{$\begin{array}{c}\mathrm{SA} \\
(\mathrm{j}=2)\end{array}$} & \multicolumn{2}{|c|}{$\begin{array}{c}\text { IV } \\
(j=3)\end{array}$} & \multicolumn{2}{|c|}{$\begin{array}{c}\text { KA } \\
(j=1)\end{array}$} & \multicolumn{2}{|c|}{$\begin{array}{c}\text { SA } \\
(j=2)\end{array}$} & \multicolumn{2}{|c|}{$\begin{array}{c}\text { IV } \\
(j=3)\end{array}$} \\
\hline & $\mathrm{CO}$ & $\mathrm{NC}$ & $\mathrm{CO}$ & $\mathrm{NC}$ & $\mathrm{CO}$ & $\mathrm{NC}$ & $\mathrm{CO}$ & $\mathrm{NC}$ & $\mathrm{CO}$ & $\mathrm{NC}$ & $\mathrm{CO}$ & $\mathrm{NC}$ \\
\hline April & - & - & - & - & - & - & - & - & - & - & - & - \\
\hline May & 62,456 & 0 & 10,4285 & 204,000 & 37,259 & 0 & 48,990 & 94,295 & 86,965 & 11,705 & 24,198 & 0 \\
\hline June & - & - & - & - & - & - & - & - & - & - & - & - \\
\hline July & - & - & - & - & - & - & - & - & - & - & - & - \\
\hline August & 106,103 & 155,673 & 123,392 & 0 & 76,505 & 150,327 & 132,131 & 0 & 140,358 & 106,000 & 94,582 & 0 \\
\hline
\end{tabular}

Table 11 - Delivery cost from hubs to communities $\left(\beta_{k j}{ }^{(t)}\right)$ under CO and NC scenarios

\begin{tabular}{|c|c|c|c|c|c|c|c|c|c|c|c|c|}
\hline \multirow{3}{*}{ Month } & \multicolumn{6}{|c|}{$\mathrm{k}=1$} & \multicolumn{6}{|c|}{$\mathrm{k}=2$} \\
\hline & \multicolumn{2}{|c|}{$\begin{array}{c}\text { KA } \\
(\mathrm{j}=1)\end{array}$} & \multicolumn{2}{|c|}{$\begin{array}{c}\text { SA } \\
(j=2)\end{array}$} & \multicolumn{2}{|c|}{$\begin{array}{c}I V \\
(j=3)\end{array}$} & \multicolumn{2}{|c|}{$\begin{array}{c}\mathrm{KA} \\
(\mathrm{j}=1)\end{array}$} & \multicolumn{2}{|c|}{$\begin{array}{c}\mathrm{SA} \\
(\mathrm{j}=2)\end{array}$} & \multicolumn{2}{|c|}{$\begin{array}{c}\text { IV } \\
(j=3)\end{array}$} \\
\hline & $\mathrm{CO}$ & $\mathrm{NC}$ & $\mathrm{CO}$ & $\mathrm{NC}$ & $\mathrm{CO}$ & $\mathrm{NC}$ & $\mathrm{CO}$ & $\mathrm{NC}$ & $\mathrm{CO}$ & $\mathrm{NC}$ & $\mathrm{CO}$ & $\mathrm{NC}$ \\
\hline April & - & - & - & - & - & - & - & - & - & - & - & - \\
\hline May & 0.288 & 0.362 & 0.288 & 0.288 & 0.288 & 0.362 & 0.352 & 0.375 & 0.352 & 0.405 & 0.352 & 0.409 \\
\hline June & - & - & - & - & - & - & - & - & - & - & - & - \\
\hline July & - & - & - & - & - & - & - & - & - & - & - & - \\
\hline August & 0.251 & 0.362 & 0.251 & 0.362 & 0.251 & 0.307 & 0.278 & 0.409 & 0.278 & 0.371 & 0.278 & 0.409 \\
\hline
\end{tabular}


Table 12 - Electricity generation and local inventories at communities under CO and NC scenarios

\begin{tabular}{|c|c|c|c|c|c|c|c|c|c|c|c|c|}
\hline \multirow{4}{*}{ Month } & \multicolumn{12}{|c|}{ Communities } \\
\hline & \multicolumn{4}{|c|}{$\mathrm{KA}(\mathrm{j}=1)$} & \multicolumn{4}{|c|}{$\mathrm{SA}(\mathrm{j}=2)$} & \multicolumn{4}{|c|}{ IV $(j=3)$} \\
\hline & \multicolumn{2}{|c|}{$z_{1}{ }^{(t)}$} & \multicolumn{2}{|c|}{$I_{1}^{(t)}$} & \multicolumn{2}{|c|}{$z_{2}{ }^{(t)}$} & \multicolumn{2}{|c|}{$I_{2}{ }^{(t)}$} & \multicolumn{2}{|c|}{$z_{3}{ }^{(t)}$} & \multicolumn{2}{|c|}{$I_{3}{ }^{(t)}$} \\
\hline & $\mathrm{CO}$ & $\mathrm{NC}$ & $\mathrm{CO}$ & $\mathrm{NC}$ & $\mathrm{CO}$ & $\mathrm{NC}$ & $\mathrm{CO}$ & $\mathrm{NC}$ & $\mathrm{CO}$ & $\mathrm{NC}$ & $\mathrm{CO}$ & $\mathrm{NC}$ \\
\hline April & 0 & 0 & 0 & 0 & 0 & 0 & 0 & 0 & 0 & 0 & 0 & 0 \\
\hline May & 171,900 & 63,947 & 74,872 & 80,689 & 306,000 & 306,000 & 127,500 & 151,955 & 92,800 & 0 & 41,283 & 0 \\
\hline June & 171,000 & 171,000 & 38,489 & 44,306 & 306,000 & 306,000 & 63,750 & 88,205 & \begin{tabular}{|l|}
92,300 \\
\end{tabular} & 0 & 21,217 & 0 \\
\hline July & 180,900 & 180,900 & 0 & 5,817 & 306,000 & 306,000 & 0 & 24,455 & 97,600 & 0 & 0 & 0 \\
\hline August & 179,700 & 0 & 200,000 & 161,489 & 306,000 & 14,185 & 200,000 & 127,500 & 97,000 & 129,240 & 150,000 & 97,000 \\
\hline September & 168,700 & 168,700 & 164,106 & 125,596 & 306,000 & 0 & 136,250 & 127,500 & 91,100 & 109,436 & 130,196 & 91,100 \\
\hline October & 178,700 & 178,700 & 126,085 & 87,574 & 306,000 & 306,000 & 72,500 & 63,750 & 96,400 & 88,480 & 109,239 & 96,400 \\
\hline November & 194,800 & 194,800 & 84,638 & 46,128 & 306,000 & 306,000 & 8,750 & 0 & 105,100 & 65,632 & 86,391 & 105,100 \\
\hline December & 216,800 & 216,800 & 38,511 & 0 & 42,000 & 0 & 0 & 0 & 117,000 & 40,197 & 60,957 & 117,000 \\
\hline January & 181,000 & 0 & 0 & 0 & 0 & 0 & 0 & 0 & 133,300 & 11,219 & 31,978 & 133,300 \\
\hline February & 0 & 0 & 0 & 0 & 0 & 0 & 0 & 0 & 122,300 & 0 & 5,391 & 51,606 \\
\hline March & 0 & 0 & 0 & 0 & 0 & 0 & 0 & 0 & 24,800 & 0 & 0 & 0 \\
\hline
\end{tabular}


Table 13 - Total and unit cost of energy production for various coordination and configuration scenarios

\begin{tabular}{|c|c|c|c|c|c|c|c|}
\hline \multirow[b]{2}{*}{ Scenarios } & \multirow{2}{*}{\multicolumn{2}{|c|}{$\begin{array}{l}\text { Assessment } \\
\text { Criteria }\end{array}$}} & \multirow[b]{2}{*}{$\begin{array}{l}\text { No biomass } \\
\text { (diesel only) }\end{array}$} & \multicolumn{2}{|c|}{ Coordination } & \multicolumn{2}{|c|}{ No Coordination } \\
\hline & & & & $\begin{array}{l}\text { With biomass, } \\
\text { hub } \\
\text { coordination, } \\
\text { and supplier } \\
\text { discounts }\end{array}$ & $\begin{array}{l}\text { With biomass } \\
\text { and hub } \\
\text { coordination, } \\
\text { but no supplier } \\
\text { discounts }\end{array}$ & $\begin{array}{c}\text { With biomass } \\
\text { and supplier } \\
\text { discounts but no } \\
\text { hub } \\
\text { coordination }\end{array}$ & $\begin{array}{l}\text { With biomass, } \\
\text { but no hub } \\
\text { coordination } \\
\text { and no } \\
\text { supplier } \\
\text { discounts } \\
\end{array}$ \\
\hline \multirow{3}{*}{ Cooperative } & \multicolumn{2}{|c|}{ Total Cost (\$) } & $1,698,889$ & $1,378,503$ & $1,517,896$ & $1,578,842$ & $1,607,675$ \\
\hline & \multicolumn{2}{|c|}{$\begin{array}{l}\text { Unit Cost } \\
\text { (\$/KWh) }\end{array}$} & 0.212 & 0.172 & 0.185 & 0.197 & 0.201 \\
\hline & \multicolumn{2}{|c|}{$\begin{array}{c}\text { Biomass share } \\
(\%)\end{array}$} & $0 \%$ & $61 \%$ & $61 \%$ & $25 \%$ & $25 \%$ \\
\hline \multirow{9}{*}{$\begin{array}{c}\text { Non- } \\
\text { cooperative }\end{array}$} & \multirow{3}{*}{$\begin{array}{l}\text { Total Cost } \\
\text { (\$) }\end{array}$} & $\begin{array}{c}\mathrm{KA} \\
(\mathrm{j}=1)\end{array}$ & 487,157 & 381,986 & 384,049 & 434,147 & 434,147 \\
\hline & & $\begin{array}{c}\mathrm{SA} \\
(\mathrm{j}=2)\end{array}$ & 950,064 & 790,581 & 793,709 & 869,678 & 869,679 \\
\hline & & $\begin{array}{c}\mathrm{IV} \\
(\mathrm{j}=3)\end{array}$ & 261,669 & 199,715 & 200,930 & 230,442 & 230,442 \\
\hline & \multirow{3}{*}{$\begin{array}{l}\text { Unit Cost } \\
\text { (\$/KWh) }\end{array}$} & $\begin{array}{c}\mathrm{KA} \\
(\mathrm{j}=1)\end{array}$ & 0.208 & 0.162 & 0.164 & 0.185 & 0.185 \\
\hline & & $\begin{array}{c}\mathrm{SA} \\
(\mathrm{j}=2)\end{array}$ & 0.215 & 0.178 & 0.180 & 0.197 & 0.197 \\
\hline & & $\begin{array}{c}I V \\
(j=3)\end{array}$ & 0.207 & 0.157 & 0.159 & 0.182 & 0.182 \\
\hline & \multirow{3}{*}{$\begin{array}{l}\text { Biomass } \\
\text { share }(\%)\end{array}$} & $\begin{array}{c}\mathrm{KA} \\
(\mathrm{j}=1)\end{array}$ & $0 \%$ & $50.2 \%$ & $50.4 \%$ & $27.1 \%$ & $27.1 \%$ \\
\hline & & $\begin{array}{c}\mathrm{SA} \\
(\mathrm{j}=2)\end{array}$ & $0 \%$ & $34.9 \%$ & $34.6 \%$ & $21.3 \%$ & $21.3 \%$ \\
\hline & & $\begin{array}{c}I V \\
(j=3)\end{array}$ & $0 \%$ & $54.7 \%$ & $55.2 \%$ & $30.9 \%$ & $30.9 \%$ \\
\hline
\end{tabular}

